Concept Paper

\title{
Future Skills of Design for Sustainability: An Awareness-Based Co-Creation Approach
}

\author{
Kirsi Hakio * and Tuuli Mattelmäki \\ Department of Design, School of Arts, Design and Architecture, Aalto University, 02150 Espoo, Finland; \\ tuuli.mattelmaki@aalto.fi \\ * Correspondence: kirsi.hakio@aalto.fi
}

Received: 30 July 2019; Accepted: 20 September 2019; Published: 25 September 2019

\begin{abstract}
Our inner, invisible dimension consisting of our values, mental models and worldviews, has been identified as a significant leverage point for transformational change, as it brings to life our actions. Accordingly, the inner dimension of sustainability has a major role in transitioning towards desirable and sustainable futures. This paper focuses on exploring what kind of methods and competences are needed to access and work with the inner dimension as part of collaborative design practices aiming for sustainable and deep change. Thus, a lesser researched, alternative perspective to design discourse, the awareness-based co-creation approach is highlighted as a potential and emerging direction for design for sustainability. By thinking across: (1) literature findings of the concept of inner dimension of sustainability; (2) existing knowledge of awareness-based transformation approaches and (3) results of an experimental case study done in the context of nature tourism, it was recognized that more examples are needed on how to enable, promote and capture participants' transformative experiences. Finally, the argument is made that awareness-based competencies should be considered as essential future skills and competences of design for sustainability.
\end{abstract}

Keywords: awareness-based approach; inner dimension of sustainability; future skills; mental models; key competences for sustainability; co-design; design for sustainability

\section{Introduction}

This article discusses future of design for sustainability from the perspective of skills and competences. In 2017 UNESCO listed eight key competences for sustainability, aiming for enabling all individuals to contribute to achieving the Sustainable Development Goals [1] These competences include:

- $\quad$ systems thinking competency

- anticipatory competency

- normative competency

- $\quad$ strategic competency

- collaboration competency

- critical thinking competency

- $\quad$ self-awareness competency

- integrated problem-solving competency

According to Rieckmann these key competencies are particularly important and essential "for thinking and acting in favour of sustainable development" ([2], p. 44). The more detailed descriptions under the bullet points demonstrate how many of these listed competencies resonate with design competences, and are in line with the characteristic skills and abilities of designers working in the 
fields of sustainability, social innovation and services as observed by e.g., [3-6]. These competences include the ability to recognize and understand relationships and to analyse complex systems, ability to understand and evaluate multiple futures - possible, probable and desirable - and to create one's own visions for the future, ability to deal with uncertainty and ability to question norms, practices and opinions, ability to facilitate collaborative and participatory problem solving, and finally ability to learn from others. Furthermore, the empathic and sensitive ability to understand, respect and relate to the needs, perspectives and actions of others can be highlighted ([1], p. 10).

Design is a change-oriented discipline equipped with capabilities to enhance and foster transformations of current conditions and solutions to preferred ones ([7], p. 111). Thus, it can be said that design processes are transformation processes where design competencies, such as "ability to look around, frame a problem, listen and collaborate, capability to make choices and solve problems, as well as make dreams that are viable in to reality" [8] are widely utilized, see also [5,9-12]. In particular, when addressing participatory design, and similar collaborative and multidisciplinary activities, design capabilities can be seen as skills of empowerment aiming at increasing people's own design capacity to co-create and influence their own lives and environments, e.g., [13,14]. UNESCO's eight key competences for sustainability are seen important to everyone to adopt, and similarly design as a culture, competence and practices can be seen as a human capacity that everyone can cultivate ([5], p. 53).

Currently, many areas of design focus on working in the fields of systemic change and transitions towards sustainable ways of organizing societies and lifestyles. According to Gaziulusoy and Ryan, these transitions and systems innovations require significant and structural changes in the systems that support society, where the systemic transformation processes require a re-conceptualization of the whole system utilizing creative skills of imagining alternative and desirable futures ([2], p. 1298). Design for Sustainability, Design for Social Innovation and Design for Services all share the above-mentioned common interests and methodological approach, even though the scale of the projects as well as time span, focus of impact and level of change diverse, see framework in [15], also [16]. In the end, collaborative and participatory design practices, interventions and events towards imagining futures and visioning for pathways and goals are always co-created here and now, in the present.

Understanding the significance of the present moment in terms of emerging future is a key, since we constantly construct our social realities through the daily experiences and interactions with others [17]. Takanen and Petrow [18] see the ongoing collective event as something that emerges moment by moment through our encounters. They use the term co-creation to describe the continuous manifestation and opening of a relational space, where we are relating with ourselves, each other and the world around us, thus making realities here and now. Central to this is to recognize how we all participate in the process of reality creation with our thoughts, feelings and actions in our relationships with others (Ibid. p. 103), and how that affects the future unfolding. Hannah du Plessis argues that unless we intervene the way our feelings, thinking and reacting become our habits, "we will continue to live from our culturally installed operating system and perpetuate our current reality" ([19], p. 2). She emphasizes that for our systems to transition towards a life-affirming world, our collective thinking and behavior must create that transition and change first. Here our behavior is only the visible tip of the iceberg, as our interior invisible world animates and brings to life our actions. (Ibid.)

This idea of mental models, the internal pictures of the world, which affect the individual and collective capabilities of learning and change, has been recognized e.g., in the fields of organizational learning and change [20,21] and identified as leverage points in systems thinking [22-24]. In systems thinking education these mental models are commonly described as deep, underlying and hidden structures behind the societal issues and planetary wicked problems. Universal Iceberg model is widely used to help contextualize the issue at hand as part of a whole system and make visible the often hidden and underlying structures, that ultimately affect the possibilities of developing lasting solutions [25]. At the bottom of the model lie the individual and cultural mental models, that are generative by nature and derive their roots from our values, assumptions, reactions and beliefs. Peter Senge argues that 
if we lack skills of inquiring into these underlying and hidden structures, both our own and others', we are limited in experiencing collaboratively with new ways of thinking [20] (p. 203).

Thus, in the light of sustainable and deep change making, this paper focuses on the competency of self-awareness, which UNESCO further describes as "the ability to reflect on one's own role in the local community and (global) society, continually evaluate and further motivate one's actions, and deal with one's feelings and desires" ([1], p. 10). In other words, ability to become aware and connect to self as well as ability to recognize one's connectedness with a larger whole. The authors of this paper see a close connection between self-awareness competency and the concept of social construction of realities through generative, individual and cultural mental models. However, traditionally designers have not been trained to address issues dealing with the inner dimension of humans, when facilitating and fostering change with above mentioned characteristic design skills and competencies. Terry Irwin points out how for instance failure to consider stakeholder conflicts regarding the different contradictory concerns, fears, hopes and desires can be a barrier to problem resolution ([26], p. 9). Thus, the motivation and contribution of this paper emerges from the momentum of developing sustainability competencies that address the deep, underlying and sometimes hidden layers of change. It seems, that including awareness-based approach and awareness-based competencies (such as self-awareness and ability to connect and act from the perspective of the whole) into transformative design practices, is a lesser researched area in design research literature. Therefore, the contribution of this paper is positioned in the intersections of inner dimension of sustainability and design.

In the next sections first the concept of inner dimension of sustainability is briefly explored through literature. Then different applications of awareness-based approach, related to change, transformative practices and co-creation are viewed to lay the basis for an exploratory case example. The discussion around recommendations towards sustainability or around awareness-based approach can be highly theoretical by nature. Hence this paper aims to bring forward how the conceptual and philosophical terms, such as self-awareness, mental models, interconnectedness and co-creation of reality can be applied in practice as part of collaborative design. The key research-question this paper aims to answer is; how awareness-based competencies and the concept of inner dimension of sustainability can be utilized in design process promoting change towards sustainable futures? And further; what are the benefits and challenges of trying to integrate such competencies with design competences and practice?

\section{Concept of Inner Dimension of Sustainability}

The inner dimension of humans related to transformational change has been mostly examined, with few exceptions, in the areas of environmental psychology and social sciences. In the following paragraphs, some of the general themes that are most interesting for the focus of this paper and that offer valuable insights are briefly introduced.

\subsection{Values and Worldviews}

Values are seen as important drivers of transformational change towards sustainability because personal and cultural values are connected to our actions. Horlings [27] links values to the context of inner dimension of sustainability which includes our personal dimension and collective cultural dimension. Collective or widely shared sustainability values and attitudes are a necessary but nevertheless insufficient condition for the achievement of e.g., sustainability goals (Leiserowitz et al. [28]). They often do not translate directly into actual behavior as people are not always aware of their values. Furthermore, there are critical gaps and barriers between expressed values or attitudes and actual behaviors both at the individual and the collective levels (Ibid., p. 439). Addressing these gaps is highly relevant regarding transitioning into positive, sustainable futures.

Worldviews too, play a fundamental role in shaping lifestyles and behaviors in these transitions ([29], p. 40). Drawing from several authors Hedlund-de Witt et al. argue that changing individual behavior and lifestyles is generally seen as a vital factor in transitioning towards a sustainable society. Worldviews can be understood as an integrative framework which we all inherently have. They can be 
described as "inescapable, overarching systems of meaning and meaning-making that substantially inform how humans interpret, enact, and co-create reality" as well as systems that "contain values and environmental attitudes". (Ibid., p. 40). Hedlund-de Witt sees the operationalization of worldviews as an approach for designing and supporting (more) sustainable pathways both locally and globally [30]. This brings our emphasis on capabilities of cultural self-reflexivity, where the capacity to inhabit and empathetically resonate with divergent worldviews plays an important role. These capabilities are seen as necessary starting point for bridging divisions, synthesizing positions and aligning perspectives toward common goals and win-win solutions [31].

\subsection{Paralyzed Mental Stages}

As a barrier to change can be the problem of the divide between our collective behavior and our collective aspirations. We are paralyzed as instruments trapped inside our current paradigms. Senge et al. suspect that none of us really, with an intent, want to destroy species as result of purchasing decisions, or want to deliberately create global warming, or prevent people gaining access to clean drinking water ([32], p. 231). In this kind of worldview, people feel losing sense of the autonomy, our will and the real ability to make choices (Ibid., pp. 231-232). The paralysis can be described as deep-freezing our ability to sense what is actually going on, almost as a defense mechanism towards the uncomfortable and troublesome issues, and thus we deny the larger consequences of our way of living. This is why personal cultivation and call to serve are seen as important capabilities in breaking the cycle. (Ibid., p.232) However, engaging in sustainability ideals and aspiration, may drive people towards unintended imperatives and actions that ultimately manifests in form of burn-outs and frustration with wasted efforts [33]. The phenomenon can be called 'environmental melancholia', a mental state, in which a person who cares deeply about the wellbeing of the ecosystem and future generations, has become paralyzed and thus cannot change his or her concerns into action ([34], p. 4). Focusing on the emotions and their effects on learning and action, Lertzman argues how in sustainability development initiatives it is essential to 'take people with' before jumping into action [35], see also [36].

Lertzman advices us to focus on the question of diverse emotional crossroads where people get confused and stuck, such as conflicting desires and motivations. She argues that these are private, emerging and inchoate places that cannot be accessed via surveys or structured interviews or facilitated focus groups. [34] (p. xiii) A process of slowing down to cultivate broader awareness and reflective practice, where connection to all life is nurtured, and the creative tension between desired future for all life and the current reality is recognized and ultimately, bit by bit tolerated ([33], pp. 97-99). Hannah $\mathrm{du}$ Plessis [19] points out how journeys of transformation have cross-roads and monsters, that are invisible and powerful, such as limiting beliefs, fears and past pain. The ability to re-create oneself by focusing on individual ways of seeing and behaving, as well as the ability to face and stay with the lived experience of the unpleasant feelings and sensations are seen as a leverage point for systemic change. (Ibid.)

\subsection{Experience of the Ecological Self}

The ability to experience the ecological construal of self [37] is "a crucial step towards changing our individual and collective relationships with the natural world" ([38], p. 93). It refers to transforming the point of reference and the orientation from which we operate and co-create our culture and society. This fundamental belief in connectedness with human beings to each other and all life forms, ecosystem and planet, can be seen as an extension of an interdependent view of the self (Ibid., pp. 100-101). In other words, experiencing ecological self means seeing yourself as part of a comprehensive biophysical / spiritual relationship, where the behavior of the individual is contingent on the conditions and state of being of others (e.g., plants, animals, other people, atmosphere and landscapes) (Ibid. p. 100). Central in the ecological construal of self is not the "inner self", but the individual's relationships with the rest of the natural environment (Ibid. p. 100) which is, really, the basic attribute of systems 
thinking competency and a prerequisite for internalizing the concept of interconnectedness of life, e.g., [22,39-41]. However, studies show that even though powerful experiences of ecological self can be achieved through various exercises, practices and participatory session, those experiences can be hard to integrate into mundane daily life or explain to friends and family ([38], p. 104). In any case, experiencing the ecological self produces heightened sensitivity towards environment, feelings of sympathy and connectedness with the others in the ecosystem as well as motivation for more conscious action.

\subsection{Summary of the Literature}

The inner dimension of sustainability has a major role in transitioning towards desirable and sustainable futures. There is an invisible, inner dimension of humans, that includes our individual and cultural values, worldviews, emotions, attitudes and beliefs, and that brings to life our actions, and thus affect greatly the way we interpret, experience and co-create reality and paradigms. Hence, in order to catalyze rapid and large-scale societal change, we need first to acknowledge the effect the inner dimension has on learning and our abilities to change.

All transformation processes have cross-roads and monsters. Focus on developing individual and cultural skills of self-reflexivity and capacity to face the challenges and the unpleasant, paralyzing feelings and sensations is required, instead of escaping them by jumping into aspirations and quick solutions. This points out to a shift to address people's inner dimension. It can be achieved by doing the inner work of sustainability and cultivating reflective practice of broader awareness and experiences of interconnected self. However, these are sensitive, silent and private inner practices that may not be accessed with traditional research methods. We are in the first steps to reach and operationalize the inner dimension as part of individual and societal transformational change.

\section{Awareness-Based Practices}

This section views different applications and methods of awareness-based approach, related to change, transformative practices and co-creation, to lay the basis for the experimental case study that follows. The term awareness-based can mean many things, depending on the context where it is used. In this paper, awareness-based perspective is linked to such transformation processes that aim for radical change. Emphasizing that we as humanity and as individuals 'must become someone different' as well as the current outcomes and solutions we create and produce to this world must fundamentally change [19,42].

Awareness-based techniques and skills are introduced here also as an approach that binds together and connects the different arguments, requests and requirements previous sections of this paper have made regarding future skills. Two main themes in this approach are: (a) the cultivation of abilities to self-awareness and (b) the ability to recognize, sense and connect to a larger collective whole, the life-sustaining web. Embracing and practicing these skills creates competencies for acting from the place of open mind, open heart and open will [42] as well as prepare favorable conditions for awareness-based co-creation of futures [19]. The main difference to many eastern philosophies and traditions focusing on cultivating skills of awareness in the present moment, is the conscious forward-looking movement and orientation of being present in action [43,44].

Many applications of awareness-based practices have roots in mindfulness and Buddhist traditions. Mindfulness skills and practices can be seen enhancing people's ability to achieve fulfillment and well-being through other means, than hedonistic thinking and material rewards [45]. Besides a meditation technique and practice, mindfulness can be viewed as a relational way of being in our everyday lives, meaning cultivating a worldview of interconnectedness and non-dualistic thinking [43,46]. Systematic reviews in the area of sustainable consumption research $[47,48]$ highlight its capacity to reduce materialistic values and promote subjective well-being, but show only promising evidence of practices of mindfulness being able to influence sustainable consumption behaviors. On the other hand, happiness studies address the same issue by recognizing and establishing a 
link between sustainability and happiness [49-51]. By cultivating skills of becoming aware of one's life-styles, inner states of being and the way consumer society defines our behavior and choices, it is possible to reinterpret the traditional relationship we have with materialism and consuming [49]. According to Escobar-Tello and Bhamra, "happiness and sustainable lifestyles are 'variables' that form an interlocking system. Therefore, triggering one characteristic will trigger another" ([52], pp. 187-188) Hence, the concept of happiness may have potential in promoting transitioning society towards sustainable lifestyles. Here design as a discipline and competency is seen to have a major role for using happiness as a seed to shape and promote these individual and societal transitions [49].

\subsection{Design and Awareness}

The intersections between mindfulness, design and design education has been recognized by few pioneers working in the field of design research [40,46,53-55]. According to Akama, the essence of interconnectedness can be found in co-design practices since it is a relational methodology ([40], p. 266). Similarly, design and mindfulness has been discovered to share same attributes of openness and interconnectedness ([55], p. 11), where openness is understood as receptivity to multiple perspectives, cultivating the skills of systems thinking and systems experience. Through her own experiences, Akama describes how she embraced the way of a practitioner, and how in her own design work mindfulness as a way of being is embedded in the way she lives, breathes, creates and becomes-with through the daily encounters and relations $[40,46]$. Rojas et al. [55] suggest that mindfulness as a self-reflective competency should be included as part of design education. It can be seen a relevant skill for designers regarding working with ethics, responsibility and uncertainty, but also as an ability to face and act in the constantly evolving, complex and challenging design environments and roles (ibid.). Similarly, the recent Transition Design framework [16] places capabilities such as mindfulness, willingness to collaborate and optimistic grumpiness under one of the core focus areas of future design competencies, called a 'new mindset and posture'. These are new capabilities but also new ways of designing that are needed in living through transitional times and societal transformation (Ibid.) In other words, competencies of mindfulness can be seen as a readiness that enables us to cultivate abilities "to receive and be part of the world in its continual becoming" ([53], p. 221), where becoming is "impermanent, interrelated and intimate, not just being aware of it" (Ibid., p. 228).

\subsection{Grounding Mindfulness}

Among others, Ericson et al. proposes that educating and maintaining new skills and relational ways of being that are shaped by awareness of choices and behaviors that promote sustainable outcomes, could contribute both to more sustainable ways of life and to greater well-being ([45], p. 78). However, in order to achieve such individual and social transformation, we need to engage with the educational and ethical core of the practice, arising from the Buddhist tradition [56]. Concepts like interconnectedness as well as ideas behind systems thinking and wisdom are very familiar to Buddhist orientation, since throughout all cultural forms of Buddhism nature is perceived as relational whole where each phenomenon is dependent on a multitude of causes and conditions. From Buddhist perspective these causes include both physical and biological factors, but also historical and cultural factors like human thought forms and values ([57], pp. 301-302). Without spiritual and philosophical grounding, "mindfulness becomes just another fashionable self-help gimmick that is unlikely to be of any lasting individual or social benefit" ([56], p. 334). Similarly, by criticizing western psychology of trying to remove mindfulness from its roots, Saarinen and Lehti [43] connect mindfulness to the concept of systems intelligence. Systems intelligence [58] is a skill where subject is able to perceive their own interdependence with their environment by simultaneously observing the influence of the whole upon themselves as well as their own influence upon the whole (Ibid., p. 1122). In this way actions of systems intelligence may be perceived as being mindful of wholes. They argue that "from this perspective, mindfulness is a systems skill—perhaps the original systems skill" (Ibid., p. 1122). 


\subsection{Collective Self-Awareness}

While the individual side of transformation and the cultivation of competencies of self-awareness has been researched from multiple angles, the collective side of the journey - the experiencing, co-creating and transforming together-has received less attention. To provide an example of one such practice we introduce Council of All Beings [59], a participatory ritual and a transformative model of experiential teaching based in Buddhist environmentalism, Buddhist meditation techniques and Buddhist law of dependent co-arising ([57], p. 300). The core exercise is a role-play activity, where creation of masks, movement and sound, in which each participant takes a role of a nonhuman being such as the sun, a rock, a plant or an animal, has a central role [38]. These non-human roles are seen as thinking and feeling creatures, "with whom it is possible to understand, strongly empathize and directly communicate" (Ibid., p. 103). Council of All Beings is one of the practices that enable the construction and interpretation of new ecological selves, described earlier, as participants form a circle where a group of 'beings', a council, speak from the first-person perspective of that being (Ibid., p. 103). The experience of ecological self is supported by the validation received from all the other participants in the workshop, as everyone receives mutual responses from others as if they were indeed the sun, a rock or a plant, which supports their interpretation of the new world and ultimately challenges their usual ways of relating and construing themselves (Ibid., p. 103).

Another framework that focuses on both trajectories of awareness-based co-creation and change is a transformation process called Theory $U[32,60]$. Having roots in mindfulness and eastern traditions, it is a social technology of 'presensing' where the transformation is based on five movements: (1) Co-initiating; stop and listen to others and what life calls you to do (2) Co-sensing; connect with people and places to co-sense the system form the whole (3) Co-presencing; listen from the source, by blending sensing and presence into mindful practice of presencing, allow the inner knowing to emerge (4) Co-creating; prototype the new by linking head, heart and hand, to explore the future by doing and finally (5) Co-evolving; embody the new by seeing and acting from the emerging whole $[42,60]$. In order to truly internalize and apply such thinking, one needs to have personal experiences of mindfulness practices that focus on competences of unlearning, emptiness and surrender (described in more detail in [53]), which resonates well with Senge's ideas of cultivating capacities of challenging and re-creating individual and cultural mental models [20]. The essence of practicing awareness-based co-creation is based on abilities to listen and sense from an inner place of connectedness and emptiness, what wants to emerge in each moment. Although one can recognize similarities in the way Theory U framework's methods are applied with e.g., the ones of collaborative and empathic design mindset and approach (see e.g., [61] on empathy process and [62] on cultivating sensitivities), traditionally design has not focused on awareness-based competences.

\section{Materials and Methods: Applying the Concepts}

As mentioned earlier, the discussion around concepts such as self-awareness, mental models, interconnectedness and co-creation of reality can be highly theoretical and everyone seems to have their own perceptions about them. Hence, the aim of this section is to bring forward how the conceptual and philosophical terms and thinking can be moved from "head to heart and hands" as embodied action and as part of collaborative design practices. Through the examples from a case study, which focused on the experimental parts of a two-year design research project, the paper tries to build an argument, why awareness-based competences and abilities to act from the inner place of connectedness should be integrated into design practices and why such competencies should be considered and cultivated in design education as important future skills.

The case study project was carried out in January/2017-March/2019 in the context of nature tourism, situated on an island called Elisaari close to the coast of Helsinki. The island is owned by City of Helsinki, but there is an independent entrepreneur-couple who work as custodians of the place, offering variety of services, such as cafe and restaurant services, rental cottages and saunas, boating services as well as producing seasonal events and courses. Characteristic to the place is that even 
though the island is free for everyone to use round the year, in practice during the winter season it is difficult to access and is mainly inhabited by the animals. Thus, the animal kingdom and the plant kingdom have a significant and respected role, and are seen as a relevant stakeholder group in the island. More precisely, nature is seen as "a healer of the body and mind", as the slogan and theme of the island goes.

In line with the slogan, the custodians had been developing their mission and service concept and wanted to focus-besides the maintenance of the infra and current services-to more specific activities related to social innovation. They had an intention to establish a community, where the work culture and service culture would be based on care and co-creation. They hoped that this intention would come to form through different kind of activities and encounters in the island, meaning working with various collaborative social projects together with local municipalities and entrepreneurs, as well as, enabling and organizing different kind of courses, camps, retreats, rehabilitation and training. The custodians wanted to respect and embrace the spirit of the place by including guiding values as a starting point for development. These values were: discovering nature, compassionate living, welcoming others, creating beauty, developing heart intelligence, new ways of working with money, developing awareness/inner work, co-creation, artistic expression and working with rhythms [of life]. A collaboration project between design researchers and the custodians was initiated due to a mutual interest towards awareness-based co-creation approach and societal transformation towards sustainable futures. Even though it is evident that the custodians practice a role of an entrepreneur in the society, they perceive their role more from systems intelligent point of view, where the actions of their business are tightly connected and related to other components of the whole. On that account, they recognize an inner calling of taking part in projects aiming for prototyping alternative futures and new paradigms.

The main methodology for knowledge creation was a research through design practice -based process, as described by Koskinen et al. [63] and Brandt and Binder [64], where different co-design experiments, experience prototyping and continuous shared reflection played a significant role. On the side, design researchers used ethnographic observation and interviews in order to get a more comprehensive understanding of the overall developments of the place. All workshop sessions were documented with photos and partly video-recorded and sound-recorded. The most significant research material however came from participants' own reflections at the end of the workshops as well as from follow-up interviews and informal discussions with the custodians, which were also sound-recorded or documented with notes. Within the interests of this paper, it is not intended to focus on reporting the whole project and its different goals, stages and outcomes, but rather to highlight how awareness-based competences were applied and explored in three exploratory phases of the project, as part of collaborative design research activities (see Table 1.). In the next sections of the paper these phases, research aims, methods and results are explained and discussed in more detail. 
Table 1. Outline of the research aims, methods and main results

\begin{tabular}{|c|c|c|c|c|}
\hline Phase & Research Aim & Methods & Participants & Main Results \\
\hline $\begin{array}{l}\text { Phase 1. Experimenting with } \\
\text { self-awareness competency }\end{array}$ & $\begin{array}{l}\text { Gather knowledge on different } \\
\text { techniques and exercises that } \\
\text { help to set the stage for more } \\
\text { awareness-based action. }\end{array}$ & $\begin{array}{l}\text { Co-design workshops with the } \\
\text { following self-awareness } \\
\text { techniques: guided moment of } \\
\text { mindfulness, writing lists of } \\
\text { occupying thoughts, visual aids } \\
\text { for becoming aware and } \\
\text { scanning the state of being. }\end{array}$ & $\begin{array}{l}30 \text { stakeholders invited by the } \\
\text { custodians including: } \\
\text { customers, season employees, } \\
\text { collaborators, local } \\
\text { entrepreneurs. }\end{array}$ & $\begin{array}{l}\text { Self-awareness exercises are } \\
\text { potential tuning-in methods for } \\
\text { co-creation and being present in } \\
\text { action. More research is needed } \\
\text { to identify how they might } \\
\text { build self-awareness } \\
\text { competency. }\end{array}$ \\
\hline $\begin{array}{l}\text { Phase 2. Experimenting with } \\
\text { concept of interconnec-tedness }\end{array}$ & $\begin{array}{l}\text { Create knowledge on ways and } \\
\text { means to apply the concept of } \\
\text { inter-connectedness into } \\
\text { co-design practices. Explore } \\
\text { how the abilities to act from an } \\
\text { inner place of connectedness } \\
\text { can be embodied in design } \\
\text { activities. }\end{array}$ & $\begin{array}{l}\text { Co-design workshops with the } \\
\text { following becoming aware and } \\
\text { co-sensing exercises: guided } \\
\text { moment of mindfulness, } \\
\text { walking meditation, embodied } \\
\text { exploration in free form to let } \\
\text { the place talk back. } \\
\text { Speculative role taking exercise. }\end{array}$ & $\begin{array}{l}\text { 1st workshop: } 7 \text { random } \\
\text { volunteers who were visiting } \\
\text { the place, recruited by the } \\
\text { custodians } \\
\text { 2nd workshop: } 16 \text { people } \\
\text { invited by the custodians from } \\
\text { their social media networks. }\end{array}$ & $\begin{array}{l}\text { Through awareness-based, } \\
\text { speculative and embodied } \\
\text { exercises, it is possible to } \\
\text { recognize one's own perception } \\
\text { of oneself as part of the whole, } \\
\text { aka experience ecological self. } \\
\text { They also have the potential to } \\
\text { give rise to transformative } \\
\text { experiences. }\end{array}$ \\
\hline $\begin{array}{l}\text { Phase } 3 \text {. Prototyping new } \\
\text { cultural mental modes }\end{array}$ & $\begin{array}{l}\text { Gather knowledge on the } \\
\text { Co-creating and Co-evolving } \\
\text { phases of awareness-based } \\
\text { co-creation process (after } \\
\text { Theory U). } \\
\text { Follow how ideas and values } \\
\text { translate into practices and } \\
\text { culture over time. }\end{array}$ & $\begin{array}{l}\text { Mentoring sessions with the } \\
\text { custodians, including: } \\
\text { co-designing the structure for } \\
\text { employee orientation-session by } \\
\text { applying Theory U principles. } \\
\text { Follow-up interviews and } \\
\text { informal discussions. }\end{array}$ & $\begin{array}{l}\text { Group of } 12 \text { new season } \\
\text { employees recruited by the } \\
\text { custodians, of which } 7 \text { were } \\
\text { followed more closely in } \\
\text { this study. }\end{array}$ & $\begin{array}{l}\text { Co-evolving phase and } \\
\text { prototyping activities, that gives } \\
\text { form to new practices and } \\
\text { culture, requires trust in many } \\
\text { forms. Ability to become aware } \\
\text { and recognize mental models } \\
\text { requires awareness-based skills } \\
\text { from everyone involved in the } \\
\text { project. How to reach and work } \\
\text { with them in co-design projects } \\
\text { needs further studies. }\end{array}$ \\
\hline
\end{tabular}




\subsection{Phase 1-Experimenting with Self-Awareness Competency}

This part focuses on how self-awareness competency was integrated in co-design practices as a tuning-in activity. The research aim of the experiments was to gather knowledge about different techniques and exercises that would help to set the stage for more awareness-based action. As there are many so called invisible mental layers people carry with them when they enter the workshop space, different ways of making them visible were explored. These layers may include a continuous flow of thought dealing with past events, future desires and expectations, but also emotions and habits of mind that can turn out to be preventing factors for genuine collaboration and visioning from the inner space of knowing, such as self-criticism, judgements, roles and fears as feeling of lack of something or as a fear towards the unknown.

Hence the idea was that addressing these mental layers would foster the creation of favorable conditions for people to authentically connect, experience together, co-create and explore desirable future visions from the emergence and orientation of present moment. These are not new ideas in design research as co-design sessions have traditionally included different kind of sensitizing and attuning activities to help participants orientate themselves to the themes of the workshop, unleash the imaginative and creative side and 'leave the everyday behind' for visioning not yet existing outcomes [65-67].

Three co-design workshops were organized in early 2017 at the University premises since it was winter season and the island inaccessible. The aim of these sessions was to envision new openings for collaboration and future ways of organizing activities in the island. The custodians invited all together 30 stakeholders from their networks to take part in these three sessions, including customers, season employees, collaborators and local entrepreneurs. The participants were selected based on their current role and connections as well as potential future roles and future connections in the island. All three workshops had similar structure where the session started with self-awareness exercises, such as guided moment of mindfulness which were then later complemented with exercises such as writing a list of occupying thoughts and jobs-to-be-done. Also, visual tools were tested, which were aimed for assisting the participants to scan their own state of being (Figure 1a,b). After the self-awareness activities participants continued with more established participatory practices such as simulation and experience prototyping (see more about the simulation method in [68] and experience prototyping e.g., in [69]) (Figure 1c). At the end of each workshop, a joint moment of reflection was held, discussing the immediate thoughts, feelings and experiences of the participants.

\subsection{Phase 2-Experimenting with Concept of Interconnectedness}

Next two co-design sessions took place in the island in spring and fall 2017, and were integrated in the seasonal events organized yearly during the national nature-days. Thus, the participants of these sessions were partly invited people and partly random visitors. Since nature, the animal kingdom and the plant kingdom have significant and respected role in the island, it was decided that the development of the nature-tourism services should be explored from the perspectives of the nonhuman stakeholders as well. To be more specific, to co-create with nature through speculative methods and co-sensing means. Such approach is very close to previously described ideas of the ecological self and method of Council of All Beings. Similar thinking and thought-provoking action were also pursued in this project. The aim of these sessions was to create knowledge on different ways and means to integrate and apply the concept of interconnectedness into co-design practices. And especially explore how the abilities to act from an inner place of connectedness can be incorporated into design activities.

The goal for the first session was to generate a map of special areas and places in the island's nature trail targeted for visitors. The idea was linked to the island's central theme of nature as a healer of body and mind, and therefore the custodians wanted to test whether such exercise would provide interesting, meaningful and experiential places on the nature trail. The goal was that by consciously engaging in a collective sensory process and utilizing different ways of knowing instead of verbal communication, participants would identify together particularly attractive, meaningful or relevant 
natural sites. Similar thinking can be found e.g., form Lapland where worship sites of ancient Sámi are marked on nature paths.

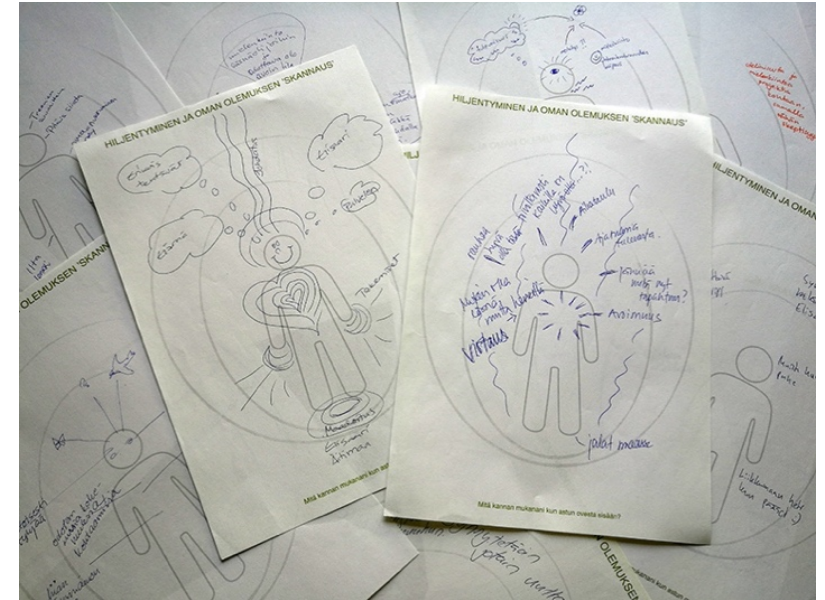

(a)

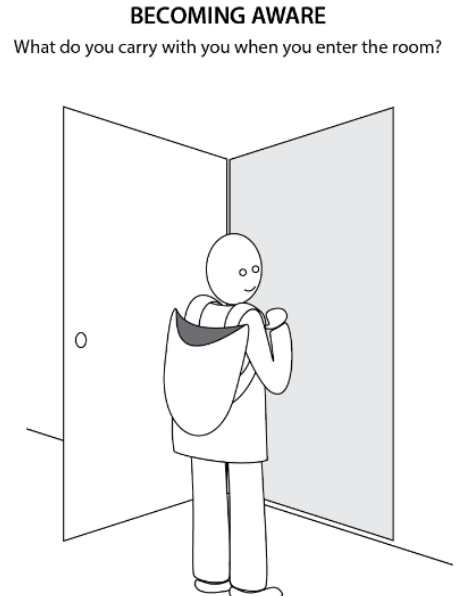

(b)

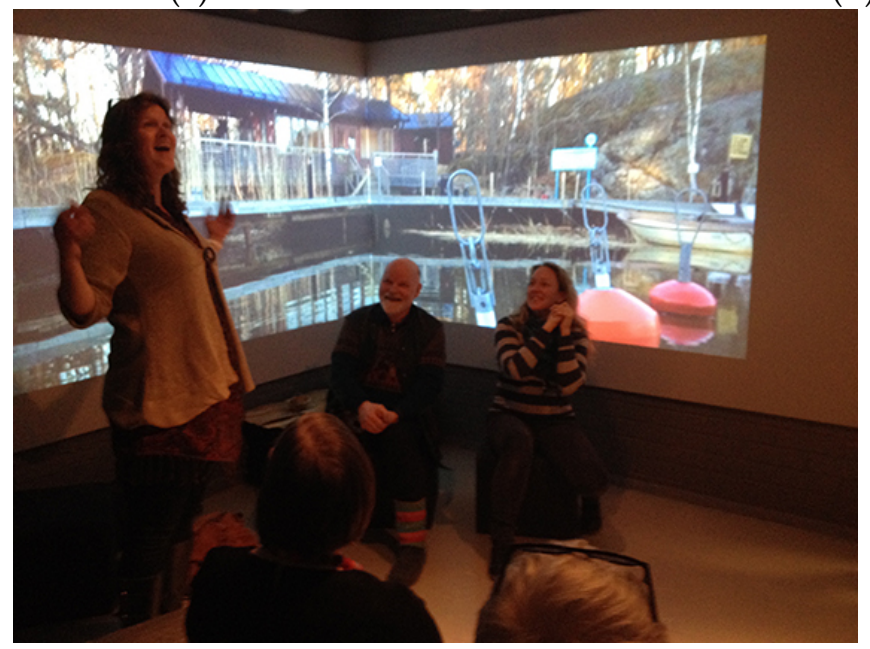

(c)

Figure 1. (a,b) Examples of the visual aids for becoming aware and scanning state of being, used in the co-design workshops; (c) Experience prototyping in simulation environment.

The custodian recruited a group of seven random volunteers visiting the island during the national nature-day, who then took part in the co-sensing activities. In this sense, these participants represented just anyone interested of the place. The session started by guided moment of mindfulness to become aware of the present moment, of one's own state of being and of one's connections to other members of the group and the surrounding world. Thereafter, the group became silent in walking meditation during which the group (including the researcher) intuitively navigated to various natural locations guided by inner knowing.

In these places, participants felt and explored the special essence of the place in free form by painting, movement, humming or simply just being still. After the silent work group intuitively and collectively named the meaningful spots for the trail by contemplating on questions like what is the essence of the place, what are the qualities and values it represents, how the place could be called and what the place suggests you to do (Figure 2).

In other words, they let the place talk back and let what wanted to emerge-emerge. Finally, the group discussed their experiences while the researcher documented the arising thoughts and atmosphere of each place, and placed them on the map of the island. The tour ended with a joint reflection at the island's main building. 


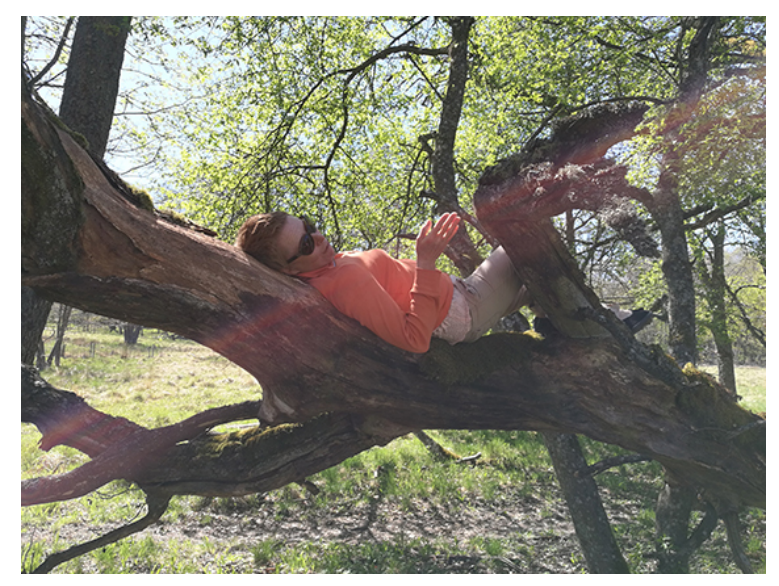

(a)

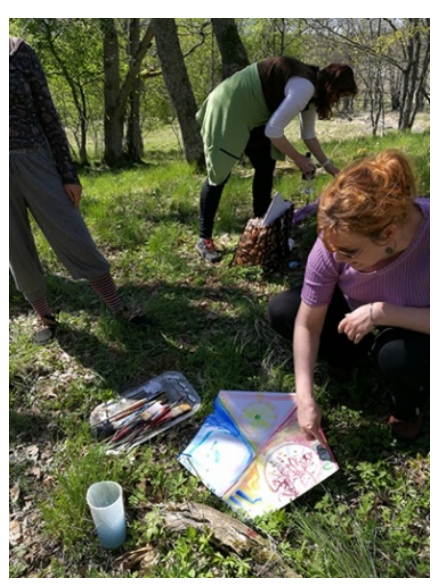

(b)

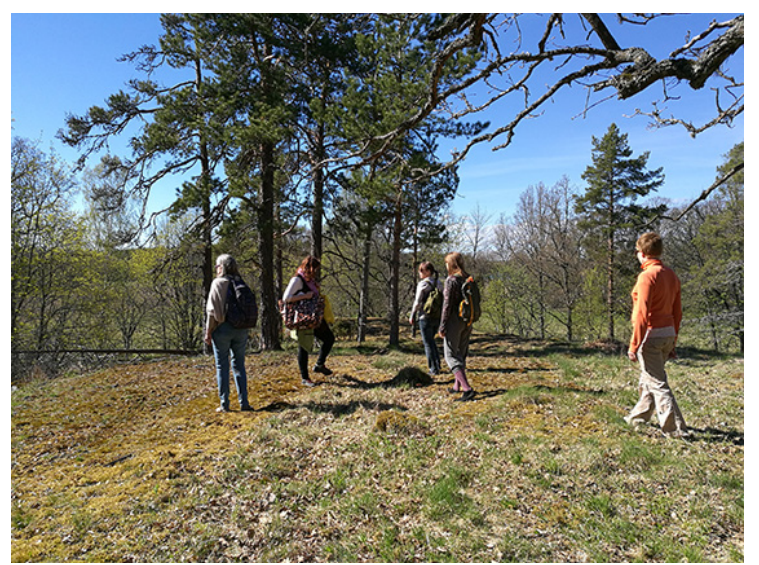

(c)

Figure 2. $(\mathbf{a}-\mathbf{c})$ Co-sensing places and areas of the island through painting, movement and walking meditation. Exploring the essence of different places; how it could be called, what are the qualities and values it represents and what the place suggests you to do there?

The second session aimed at exploring nature tourism services from the perspectives of both human tourists as well as nonhumans such as animals, plants, rock, nature elementals and historical figures of the Island (Figure 3). The workshop could be seen as a provotype by nature, as provotypes in general are defined as means that distance us from the current situation by projecting visions of potential worlds or by proposing solutions that would change practices [70]. Thus, the provocative experiment sought to highlight the human-centered point of view of conventional service design practices as well as the relative short-term perspectives of development.

The custodians send an open invitation to their social media networks and eventually recruited 16 volunteers to take part in the activities. The participants were in general people who felt they wanted to spend the day by celebrating national nature-day in the island and were also interested in taking part to the research activities. For some the place was very familiar and for others it was an opportunity to visit the place for the first time. At the beginning of the workshop participants were asked to choose and embrace one of the above-mentioned roles by using similar attuning methods like walking meditation than was utilized in the previous session. The task of role taking were seen as "becoming from the perspective of otherness". In such exercise the participants had to engage, to the best of one's ability, with inventive and speculative activities. Since humans cannot alter their consciousness or state of being for becoming a nonhuman entity or a nature element, they had to harness their personal experiences and perceptions of the role as vehicles for speculative thinking [71]. These became thus the evidences, lures and hints for constructing an overall experience, the feeling and state of mind of how it might feel, through the embodied experience, to be the other. Parisi describes 
such exercise as an event where imagination outruns direct observations, "venturing towards the limits of the observable where thought becomes experimental and experiential of the future." (Ibid., p. 237). The researcher took on the role of a journalist of a travel magazine and asked the participants (human-centered) questions related to development of nature tourism and service design, such as how the rock has contributed and invested in the user experience of the visitors, or how a capricorn has participated in the development of services provided in the island, or how the oak tree has marketed its services to international tourists. The group toured the island to discuss nature tourism services at three central locations, which was then followed by a joint reflection phase.

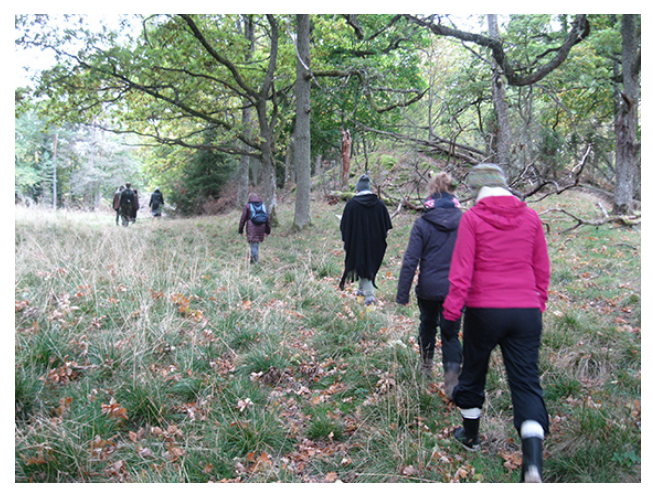

(a)

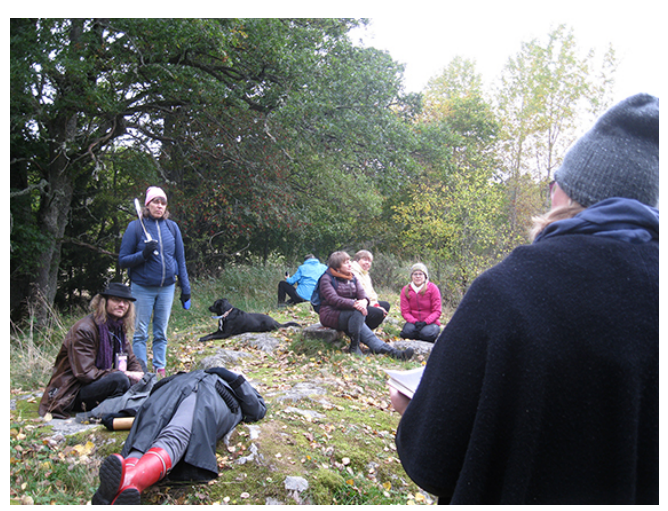

(b)

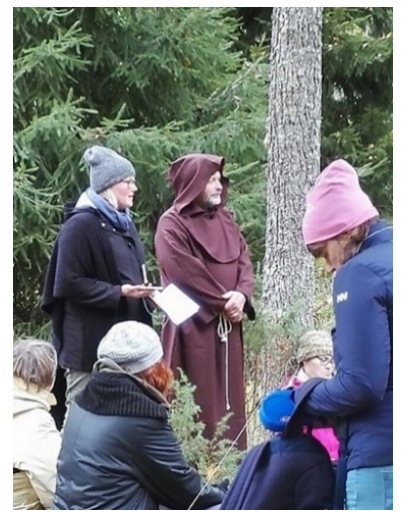

(c)

Figure 3. (a) Group attuning to the roles by walking meditation; $(\mathbf{b}, \mathbf{c})$ Group of participants exploring nature tourism services from the perspectives and roles of human tourists as well as animals, plants, rock, nature elementals and historical figures of the place.

\subsection{Phase 3-Prototyping New Cultural Mental Modes}

This section explores the organic and uncertain phase of prototyping the new by embodying the ideas generated in the previous phases. Thus, the research aim was to gather knowledge of the Co-creating and Co-evolving phases of an awareness-based co-creation process (after Theory $\mathrm{U}$ ), and follow how ideas and values translate into practices and culture over time.

The context of nature tourism was explored in this phase from the perspective of co-creative and caring work culture. More precisely, the focus of collaboration was to explore how awareness-based co-creation methods could be utilized in season employee recruiting and orientation practices as vehicles for translating the island's values of work culture into action. These values generated by the custodians were communality, collaboration, ecology and beauty.

The role of design researcher had evolved during the project from first being a facilitator, then co-creator to eventually becoming a mentor and 'crystallizer', as the custodians expressed it. Thus, in this phase the role of design research was to act as a mirror reflecting and following the prototyping phase as well as the co-evolving of the place. This included following how practices 
and tools used in the earlier phases, were then later adopted and applied by the custodians in their own work. With design researcher mentoring in the background, the custodians published a job section on the island's website, whereby they hoped to attract like-minded people who shared similar cultural interests and values as the values of the island were. Later, custodians had a mentoring session with design researcher, where they co-designed the structure for an employee orientation-session by applying Theory U principles. In line with Manzini [5], who reminds us that it is essential for designers to focus on the capacity building of the place and leave the tools and practices behind, custodians then facilitated the session by themselves. 12 new seasonal employees took part in the orientation-session, where they had a significant role in co-creating content and meaning from their own perspectives to the values presented by the custodians. These advanced values were then used as the basis for co-creating new work and service culture.

During the recruiting process the 12 employees had been dived into two groups. A seven-persongroup taking care of the Café and cleaning on the island and a five-person-group taking responsibility of the island's restaurant services. In one of the follow-up interviews custodians reported how the seven-person-group had been very active and engaged in the orientation-session activities compared to the other five-person-group, which later revealed to be an interesting observation.

Throughout the summer season the aforementioned values started to emerge in various forms. It turned out that the group of seven employees had developed a sense of shared responsibility and solidarity among themselves. They actively helped each other even beyond job descriptions and areas of responsibilities, and self-directedly took care of tasks they felt needed to be done in order to produce fluent customer experiences and run the island's services smoothly. Independently as a group they manifested, without asking instructions or receiving pre-done employee manuals, a caring atmosphere and work culture that became alive through their actions and ways of encountering each other. Naturally the culture extended and was perceivable to customers and visitors as well, for which reason the group gained a great amount of positive customer feedback. One example of their manifestations of culture of care and co-creation were bakery bags that the group started to decorate amongst themselves, inventing inspiring poems and illustrations into the bags. When they were asked by the custodians what was the meaning of such activities, the group explained them as representations of value of beauty (Figure 4). The difference to the five-person-group, who had not been active during the orientation session, was notable. They shared none of the experiences of solidarity amongst themselves or sense of togetherness, nor similar customer-feedback.

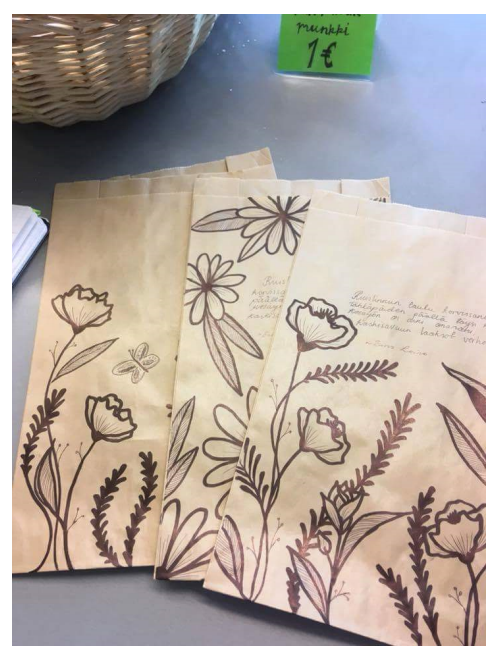

(a)

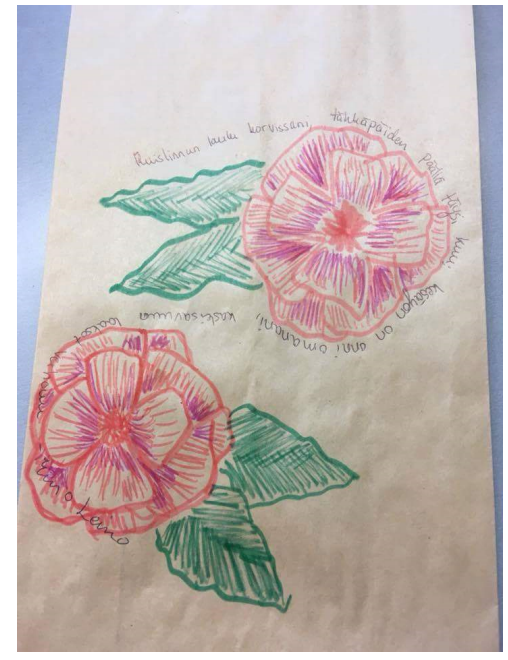

(b)

Figure 4. (a,b) Manifestations of culture of care-poems and drawings on bakery bags made by the season employees as representations of value of beauty. 
In the following fall 2018 the custodians organized a feedback event for the season employees to discuss and reflect together on the past experience. These reflections were then later reported to design researcher in follow-up interviews.

\section{Results and Key Findings}

In the following the results and some key findings of the three phases are viewed from different perspectives; from the perspective of design research, from the perspective of participants' experiences and from the perspective of project outcomes.

\subsection{Results of the Phase 1}

When the participants were asked during the reflection phase, how they perceived the role of the self-awareness exercises, only a few of them felt that these exercises had an impact on other events in the session. Instead, most of them in all of the workshops reflected mainly on the inspiring and novel simulation experience, where they were able to express themselves through improvisation and acting. The outcomes of these sessions included ideas such as rehabilitation-camps bringing together marginalized youth and lonely elderly people, island wedding -concept, exotic nature tourism service packages for international customers and extended service offerings to cover all seasons of the year. During one of the follow-up interviews in summer 2018, the custodians reflected the role of these co-design workshops as cultivating seeds of future. They saw how some seeds had already taken form and some were continuing to sprout and develop in different contexts and projects over time.

From a design research perspective, the main contribution of these workshops was that they were valuable first experiments on how to go about introducing and integrating self-awareness exercises in co-design practices. The way in which, the sometimes elusive, theme of self-awareness was presented in the workshop seemed to work quite well. Visualizing the abstract and intangible essence of the mental and emotional layers, which are subjective experiences by nature, made it easier in general to perceive, address and discuss about them in collaborative setting. When asked, participants seemed to use fairly easily the provided visual aids for self-awareness, by translating their current state of being, thoughts and feelings into form of written texts and drawings with the help of the metaphor of scanning themselves. Also, based on the material, it seems they didn't have difficulties in understanding the assigned tasks, or following the instructions or completing the tasks. Although the participants were not able to make connections between these activities and the rest of the practices in the workshops, the enthusiastic and liberated atmosphere in each workshop demonstrates their potential as tuning-in methods for co-creation. Even though the participants reflected almost solely on the engaging experience prototyping activities and the simulation environment, based on the quantity and the viability of the outcomes produced in the sessions, the action-oriented overall atmosphere and the participants surprisingly extensive ability to throw themselves into improvisation and drama exercises, it can be identified that the tuning-in phase of the workshops had been somewhat successful. In this way, based on external observations, asking the participants to pay attention to the present moment and to become aware of themselves helped to empty their minds from the outside world events and leave behind the everyday. In other words, it helped them to become present in action and listen what wanted to emerge in each moment.

A challenge is that these findings correlate with a long tradition of research done in design field and further research needs to be made whether the self-awareness practices in particular are able to produce distinctively different results compared to the existing knowledge in co-design research. Furthermore, self-awareness exercises in this form, with the visual aids typical of design workshops, remained quite superficial. Even though it was good to bring forward the inner dimension and how it affects the way we experience and co-create the present and the future, there is no evidence these exercises helped in self-awareness capacity building. Nor did they enable such transformative experiences to emerge that would have had far-reaching implications for the participants or for the project. 
To summarize, self-awareness exercises are potential tuning-in methods for co-creation and being present in action. However, more research is needed to identify how they might build self-awareness competency.

\subsection{Results of the Phase 2}

Although the map created in the first workshop was not implemented as such on the island, custodians noted that the idea of marking special areas and places on the nature trail is still in the making for a slightly different target group of retreat customers. Similarly, even though the initial focus of the second workshop was to co-create nature tourism services from the perspectives of both human and nonhumans, no new service concepts per se were ideated. Instead, it became evident quite quickly during the sessions, that the results and meaning of these workshops had more to do with challenging the way people experience, relate and connect with nature and nonhumans, and how they perceive themselves as separate and independent individuals in relation to the rest of the environment and beings.

Many challenges emerge from the academic side of the discussions, such as explaining the phenomena and subjective experience of becoming from the perspective of otherness, but it seemed that participants had no difficulty in playing along and engaging with the provocative exercises. However, some of them had challenges in the second workshop regarding the task of role taking. This was mainly because of the radically different essence of the roles, such as a tree or a plant, but also for the amount of speculative effort required to imagine alternative forms of communication. Even though not all of the participants deeply payed attention to embracing their role, but instead speculated nature tourism in the island from somewhat human-centered perspective, the session served its purpose in any case as thought-provoking intervention. All the participants were engaged in the reflection phase regardless of the depth of their performance during the action. One of the key points that came up in the reflections was how such activities related to sensing from the whole and exploring with the concept of interconnectedness, could be seen as actions of care. More precisely, they were seen as embodied experiences that remind people to view the otherness, nature and nonhumans with changed eyes. It was proposed how such exercises-entering into the spirit of the natural worlds, listening and thinking from a new perspective-could be an educational approach or a service product in itself. All in all, the participants reflected the experience as "unifying encounter with the whole", since it forced them to drift away from the constant mental noise and chatter-mind, typical for human experience, and instead pay attention on the experience arising from the silence. In short, as one of the participants put it: "something moved internally, which is difficult to describe, but which is somehow visible and perceptible to others as well".

These somewhat incautious experiments, regarding to the way they were organized with open-minded and adventurous attitude, were seen as manifestations of the possible future culture and its values, where nature is seen as relevant stakeholder as humans in collective world-making. During the reflections participants then expanded the idea of future culture to ponder how in this future culture, care as mutual and communal action would manifest in all types of encounters, between humans and nature elements, as well as among co-workers and customers. In the last follow-up interview in spring 2019 one of the custodians noted, how the idea of co-sensing and co-creating with nature have laid basis for a nascent and ever-growing culture where e.g., event-organizers have applied similar thinking into their own activities. She also mentioned how speculative exercise of becoming from a perspective of the other, such as rock, has gradually over time opened up new layers of experiences and insights for her, that affect the way she experiences nature in her personal life but also professionally as the custodian and hostess of the place. Thus, it might be that central in approaches like explained above is to give space and time for personal associations to evolve. Meaning, trusting the unavoidable and internal, ever-evolving personal transformation process.

From the perspective of design research, organizing and facilitating such exercises where the concept of interconnectedness was applied and situated in real-life context, required shifting into a 
completely new approach and mindset of letting go and trust. More precisely, letting go of the idea of being in control of the situation and trusting the emergence of happenings. Opposite to more traditional research settings, this meant trusting that all the right people will arrive to the sessions, all the right thigs will happen what needs to happen and trusting the collective awareness of the social field [32,42], that what wants to emerge will emerge. This new mindset thus allowed design researcher-the first author of this paper-to transition from some-one being in charge and an external observer to some-one becoming an equal co-creator of reality with the rest of the group. In other words, surrendering to the collective, lived experience and aligning with the presence, spirit and culture of the island, which at the end is the key to practicing awareness-based co-creation. Just as one of the custodians and one of the participants had described above, after these workshops something had moved internally in a way that there was no going back, what could also be called as a transformative experience.

To summarize it seems that through such awareness-based, speculative and embodied exercises, it is possible to recognize one's own perception of oneself as part of the whole, aka have experiences of interconnected or ecological self. This kind of exercises also have the potential to give rise to transformative experiences.

\subsection{Results of the Phase 3}

When reflecting the past experiences in one of the follow-up interviews in fall 2018, the custodians were astonished of the events of the past season as they compared the experience to previous years. It had turned out, that for most of the employees within the seven-person-group, this had been their first experience of a summer job and thus working life in general. Coming back to the values of communality, collaboration, ecology and beauty they had worked with during the orientation session, it can be seen how these values appeared and came to life in different ways in the group's activities. Together the seven-person-group had discussed with the custodians that since they didn't have previous experience how a job should look like, or how one should act in work place, it had given them open possibility to co-create the practices as they wished. In other words, since they didn't have a pre-existing cultural mental model of how work culture or work relationships should be like, they were able to put in practice the principles of awareness-based co-creation. They prototyped their experiences by linking head, heart and hand and embodied the new by co-evolving and by acting from the whole. Furthermore, they socially constructed the reality and culture they wanted to embody without limiting habits of mind or restrictive past experiences. As an outcome, all of them wished to return working together for the next season.

Reflecting the interaction between the custodians and this group of young employees revealed some key elements that need to be considered when working with concepts of mental models and co-creation of reality. One of the findings related to becoming aware of the mental models was that there is a need for an external observer such as design researcher, to bring forward the existence as well as the various forms of manifestations of these mental models at different stages of the project. The occurrence of mental models can only be detected through mundane actions, reactions, encounters and decisions of people. However, as the custodians reflected when people are in the middle of work activities or involved in hectic tasks, awareness of the self and the models behind one's action usually goes unnoticed. It takes skills and abilities to be present in action, which is generally achieved through practicing self-awareness and mindfulness.

Regarding the prototyping of new culture by co-creating preferred realities through social encounters, an important element that came up in the reflections with the custodians was trust, similar to the second phase findings. For the custodians this meant trusting the emergence of the process without interfering, trusting people's abilities to self-directly co-create desirable outcomes, trusting the synchronicity of life that there are always the right people and resources present and thus ultimately trusting the interconnectedness and systems intelligence of life. In other words, an ability to co-sense and let go of control of the events was needed which was a major learning experience for them. All in 
all, this kind of mentality is a fundamentally different one compared to the dominant and prevailing work cultures and development approaches of our current paradigm and western society.

Mental models are typically not addressed or researched in collaborative design projects, nor have designers been trained to work with them. Even though the experiences gained from this phase were just preliminary observations on one hand, how the mental models affect the co-creation of reality, and on the other, how they could be utilized in developing new solutions and alternative ways of operating, they provided insights and new research questions for further explorations.

To summarize, co-evolving phase and prototyping activities that gives form to new practices and culture requires trust in many forms. In this process, an ability to recognize individual and cultural mental models is an awareness-based skill that should be cultivated and educated to everyone involved in the project. Thus, how to reach and work with mental models in co-design projects needs further studies.

\section{Discussion}

Based on literature findings, it has become evident that the inner dimension of sustainability has a major role in transitioning towards desirable and sustainable futures. More precisely, the inner dimension of humans that contain the hidden and generative mental structures and worldviews, and that brings to life human actions. Thus, a shift in people's inner dimension is needed in order to catalyze transformational, individual and societal change. It is part of our collective responsibility as a society to develop skills and competencies to inquire, reach and operationalize these invisible, inner dimensions. In addition, it is a task of collective capacity building to prepare us to better face the challenges and the unpleasant, paralyzing feelings caused by our current paradigm and world situation, instead of escaping the them by jumping into aspirations and quick solutions.

Albert Einstein has famously noted: "No problem can be solved from the same consciousness that created it. We have to learn to see the world anew". We need to push the boundaries of the ways we approach and solve problems, and we need to search for alternative ways of co-creating future visions. As Donella Meadows pointed out in her renowned speech Down to Earth already in 1994 [24], implementing more technology or relying on economics and free markets is not going to solve our planetary problems. Instead we need such cultural mental models and skills, that allow visioning from the deepest level of the heart and soul, beyond the individual and collective fears, disappointments, cynicism and short-term self-centered visions such as growth, all deriving from rational left brain thinking (Ibid.). Arriving in such place and state of being requires personal growth and training in self-awareness competencies as well as transformative experiences and practices that help individuals sense the system from the whole. Senge argues, that competencies and mastery in such awareness "leads to an increased sense of beingness, awareness of the present moment, both what is happening within us and outside of us, and to heightened experience of generativeness, of being part of the creative forces shaping one's life" ([20], p. 375). Hence, here is a need for reflective practices of cultivating skills of broader awareness and experiences of interconnected, systems intelligent self.

This paper argues that awareness-based competencies are skills of sustainable future societies, cultures and people, that are central of sustainable change making and co-creation of desirable futures. In line with arguments made in literature regarding sustainability competences $[1,2]$ they are seen as important elements for thinking and acting in favour of sustainable development, as well as competencies that everyone can adopt and everyone should cultivate. This paper however has focused on exploring how designers and design discipline could adopt, cultivate and integrate them in the collaborative design practices.

Awareness-based practices combined with speculative exercises of becoming someone different continues and deepens the discussion of design empathy. In empathic design, the point of departure is in individual's experiences, and through capturing them, seeking reflections of possible future solutions. What is essential is to try to see a beyond the surface, on what is meaningful. It is also critical to recognize through what kind of lenses interpretations of individual's experiences are done, 
e.g., $[61,62,72,73]$. While empathic design includes experiential and emotional components, it does not refer to an uncritical and intuitive process of feeling other's emotions. Instead, it is a conscious and rational design process that guides actions and decision making. Similarly, in collaborative design empathy and sensitivity in participants' experiences as point of departure is needed. Sensitive co-design facilitation aims at supporting participants in sharing their experiences to face a challenge together and seek ways to move towards a commonly agreed direction. Although empathic design, i.e., sensitivity on individuals, uncovering and understanding what is meaningful etc., share similarities with awareness-based approach and the concept of inner dimension of sustainability, they have not been discussed previously in the connection of empathic design competence. There is a gap on one hand, towards making better connection with systemic thinking [74], and on the other, towards creating a deeper awareness of individual's inner dimension of sustainability. Such discussion deepens the understanding of empathy being an experience between separate parts towards perceptions where one experiences more and more of the interconnectedness of life and sees wholes rather than parts ([20], p. 375).

As future making regardless of the scale and time-frame happens here and now, in the present, understanding the significance of the present moment in terms of emerging future is a key, since we constantly construct our social realities through the daily experiences and interactions with others. Meaning new practices and ways of living, that come to life through the daily (human-size) encounters. This paper brings forth an alternative approach to the prevailing practices of visioning future, where future conventionally is seen as a continuum and a part of linear conception of time. Where past events and future aspirations occupy our perceptions of how thigs could be and should be, leaving no space for openness and listening. Instead, what matters in awareness-based co-creation is the ability to become present in the moment and ability to recognize how reality is constantly being shaped through our experiences. Therefore, silencing the chatter-mind and listening what wants to emerge is essential, in order to our collective future to be created from the place of inner knowing and from the collective experience of interconnectedness. It has to do with the ways and means of accessing individual and cultural generative mental models, such as assumptions about what a job description and work culture should be, or how to learn competencies to recognize and engage with one's own interconnection with others and start co-creating from that altered state of being. It is about creating new reference points and orientation from which we operate and where we base our paradigm and culture. This is also a question of capacity building in design education. Designers as facilitators of change, working with projects that foster societal transformations need to adopt such new orientation and mental models. Alongside the notions of Akama $[40,46,53]$ this includes the ability to surrender to experiencing the situated becoming of a context and a place, ability of let go of the mindset of being in control, and shift from facilitating co-creation to awareness of being an equal co-creator of realities, and finally an ability to trust the process, people, synchronicity and emergence of life.

Results of the experiments presented in the case study revealed some promising findings regarding how awareness-based competencies and the concept of inner dimension of sustainability could be utilized in collaborative design process. In the frame of this paper, the main observation lies in the cultivation, fostering and facilitation of such transformational experiences, that are able to affect and change worldviews, mental models and build inner capabilities. In order to understand the core meaning and essence of this kind of thinking and doing, one needs first to have firsthand experiences of awareness-based practices. Experiences such as connecting to self, sensing the interconnectedness of life, sensing and speculating from the perspective of otherness or listening from the collective whole, are purely subjective experiences which cannot be rationalized by reading about them or making observations from outside. They aim for a holistic transformative experience, that can be by nature a very rapid moment of change or on the other hand, a cumulative and emergent process, revealing again and again new layers of insights. Either way, as a result there is an awakening of becoming someone different. A self-realization, that one can no longer return to what he or she used to be. And an understanding, that one can no longer use the same reference points and orientation. In other words, 
it is not enough that one has external knowledge of these concepts, instead one needs to embody them to be able to construct the new view of the self.

However, there are many limitations to this study, especially with regard to the empirical parts of the research. Due to the less researched nature of the topic as well as the experimental research approach, especially the implementation of awareness-based methods, the topic was only scratched on the surface. For the same reason, the results of the experiments remained rather superficial. Thus, more focused, systematic and critical research needs to be made in order to better understand how the concept of inner dimension of sustainability and awareness-based co-creation approach can be addressed as vehicles of deep individual and cultural change. We also need more examples on how to set the stage and create enabling factors and practices for transformative experiences to emerge and how to capture for long term change.

\section{Conclusions}

This paper started by highlighting UNESCO's call for application of the key competences for sustainability, such as self-awareness, for thinking and acting in favor of sustainable development [1]. Many researchers from different fields have indicated the importance of the inner dimension of sustainability related to this conversation, however there are only few examples on what the acting part and implementation could mean in practice. This paper contributes to these discussions by bringing forth a lesser researched area in design research, the awareness-based co-creation approach. By thinking across: (1) literature findings of the concept of inner dimension of sustainability, (2) existing knowledge of awareness-based transformation approaches and (3) results of an experimental case study done in the context of nature tourism, the argument was made that awareness-based competencies should be considered as future skills of design for sustainability.

The findings of this paper bring significant new insights to the design for sustainability conversations on how to take the invisible, inner dimension of humans into account as a generative and transformative element in collaborative design processes. Also, the paper contributes to our knowledge of awareness-based approaches as development practices, which has traditionally not been an area of expertise in design.

Finally, the purpose of this paper is not to claim that awareness-based practices and co-creation approach alone can solve the world's wicked problems. Nor are they the only methodological approach to address individual and collective sustainable change in development projects. However, awareness-based competencies such as self-awareness and ability to act from an inner place of connectedness, can be considered as important future skills. Skills that cannot be ignored in the current planetary situation and moreover, skills that design education and the future of design for sustainability cannot bypass.

Author Contributions: Both authors were involved in the conceptualization of the paper, however the initial idea, methodology, conducting the research, analysis and writing — original draft preparation were done by K.H. T.M. was responsible for writing - review and editing as well as contextualizing the findings to existing design research literature and overall supervision.

Funding: This research received no external funding.

Acknowledgments: The authors wish to thank Idil Gaziulusoy for the encouraging and constructive discussions on the initial idea as well as Teija Vainio and the anonymous reviewers for the helpful comments during the development of the manuscript. In addition, the authors wish to thank all the workshop participants and collaborators, especially the custodians of the Island Elisaari, for their open mind and open will to engage themselves into experimental research practices.

Conflicts of Interest: The authors declare no conflict of interest. 


\section{References}

1. UNESCO. Education for Sustainable Development Goals_Learning Objectives; United Nations Educational, Scientific and Cultural Organization: Paris, France, 2017; Available online: https://unesdoc.unesco.org/ark: /48223/pf0000247444 (accessed on 6 May 2019).

2. Rieckmann, M. Learning to transform the world: Key competencies in Education for Sustainable Development. In Issues and Trends in Education for Sustainable Development; Leicht, A., Heiss, J., Byun, W.J., Eds.; United Nations Educational, Scientific and Cultural Organization: Paris, France, 2018; pp. 39-56. Available online: https://unesdoc.unesco.org/ark:/48223/pf0000261445 (accessed on 6 May 2019).

3. Gaziulusoy, A.I.; Ryan, C. Roles of Design in Sustainability Transitions Projects: A Case Study of Visions and Pathways 2040 project from Australia. J. Clean. Prod. 2017, 162, 1297-1307. [CrossRef]

4. Gaziulusoy, A.I.; Erdoğan Öztekin, E. Design as a Catalyst for Sustainability Transitions. In Proceedings of the DRS International Conference Series 2018, Limerick, Ireland, 25-28 June 2018; pp. 1041-1051. [CrossRef]

5. Manzini, E. Design, When Everybody Designs: An introducTion to Design for Social Innovation; MIT Press: Cambridge, MA, USA; London, UK, 2015.

6. Sangiorgi, D.; Prendiville, A. Designing for Service: Key Issues and New Directions; Bloomsbury: London, UK, 2017.

7. Simon, H.A. The Sciences of the Artificial, 3rd ed.; MIT Press: Cambridge, MA, USA; London, UK, 1996.

8. Manzini, E. The Politics of Everyday Life: How to Implement a Design-Based Collaborative Democracy. 2017. Available online: https://www.youtube.com/watch?v=s-KL1zSpr2E (accessed on 13 November 2018).

9. Lee, J.-J.; Jaatinen, M.; Salmi, A.; Mattelmäki, T.; Smeds, R.; Holopainen, M. Design choices framework for co-creation projects. Int. J. Des. 2018, 12, 15-31.

10. Cross, N. Design Thinking: Understanding How Designers Think and Work; Berg Publishers: Oxford, UK, 2011.

11. Cross, N. Designerly Ways of Knowing: Design Discipline Versus Design Science. Des. Issues 2001, 17, 49-55. [CrossRef]

12. Brown, T. Change by Design: How Design Thinking Transforms Organizations and Inspires Innovation; HarperCollins: New York, NY, USA, 2009.

13. Simonsen, J.; Robertson, T. Routledge International Handbook of Participatory Design; Routledge: New York, NY, USA, 2013.

14. Sanders, E.B.-N.; Stappers, P.J. Co-creation and the new landscapes of design. Co-Design 2008, 4, 5-18. [CrossRef]

15. Ceschin, F.; Gaziulusoy, I. Evolution of design for sustainability: From product design to design for system innovations and transitions. Des. Stud. 2016, 47, 118-163. [CrossRef]

16. Irwin, T. Transition design: A proposal for a new area of design practice, study, and research. Des. Cult. 2015, 7, 229-246. [CrossRef]

17. Berger, P.L.; Luckmann, T. The Social Construction of Reality; Penguin Books: New York, NY, USA, 1966.

18. Takanen, T.; Petrow, S. The Power of Encountering-A Story of Co-Creative Process Inquiry; OGE, Bookwell Oy: Porvoo, Finland, 2013.

19. du Plessis, H. The Mindset and Posture Required to Engender Life-Affirming Transitions. Transition Design Symposium. Carnegie Mellon University: Pittsburgh, PA, USA, February 2015. Available online: https://www.academia.edu/28391321/The_Mindset_and_Posture_Required_to_Engender_LifeAffirming_Transitions (accessed on 6 October 2018).

20. Senge, P.M. The Fifth Discipline: The Art and Practice of the Learning Organization; Doubleday: New York, NY, USA, 1990.

21. Senge, P.M.; Kleiner, A.; Roberts, C.; Ross, R.B.; Smith, B.J. The Fifth Discipline Fieldbook: Strategies and Tools for Building a Learning Organization; N. Barley Publishing: London, UK, 1994.

22. Meadows, D.H. Thinking in Systems: A Primer; Earthscan: London, UK, 2008.

23. Meadows, D.H. Leverage Points: Places to Intervene in a System; The Sustainability Institute: Stellenbosch, South Africa, 1999; Available online: http://donellameadows.org/wp-content/userfiles/Leverage_Points.pdf (accessed on 10 May 2019).

24. Meadows, D.H. Down to Earth. A Speech Given at Sustainability Conference in Costa Rica; Donella Meadows Institute: Elgin, IL, USA, 1994; Available online: http://donellameadows.org/archives/envisioning-asustainable-world-video/ (accessed on 10 May 2019). 
25. Iceberg Model. Available online: http://donellameadows.org/systems-thinking-resources (accessed on 10 May 2019).

26. Irwin, T. The Emerging Transition Design Approach. In Proceedings of the Design Research Society International Conference, Catalyst, Limerick, Ireland, 25-28 June 2018.

27. Horlings, L.G. The inner dimension of sustainability: Personal and cultural values. Curr. Opin. Environ. Sustain. 2015, 14, 163-169. [CrossRef]

28. Leiserowitz, A.A.; Kates, R.W.; Parris, T.M. Sustainability Values, Attitudes, and Behaviors: A Review of Multinational and Global Trends. Annu. Rev. Environ. Resour. 2016, 31, 413-444. [CrossRef]

29. Hedlund-de Witt, A.; de Boer, J.; Boersema, J.J. Exploring inner and outer worlds: A quantitative study of worldviews, environmental attitudes, and sustainable lifestyles. J. Environ. Psychol. 2013, 37, 40-54.

30. Hedlund-de Witt, A. Worldviews and their significance for the global development debate: A philosophical exploration of the evaluation of a concept. Environ. Ethics 2013, 35, 133-162. [CrossRef]

31. Hedlund-de Witt, A.; Hedlund-de Witt, N.H. Towards an integral ecology of worldviews: Reflexive communicative action for climate solutions. In Integral Ecologies: Culture, Nature, Knowledge, and Our Planetary Future; Mickey, S., Kelly, S.M., Robert, A., Eds.; SUNY Press: New York, NY, USA, 2013; pp. 305-344.

32. Senge, P.; Scharmer, C.O.; Jaworski, J.; Flowers, B.S. Presence: Human Purpose and the Field of the Future; SoL: Cambridge, MA, USA, 2004.

33. Schley, S. Sustainability: The Inner and Outer work. In Learning for Sustainability; Senge, P., Laur, J., Schley, S., Smith, B., Eds.; SoL: Cambridge, MA, USA, 2006; pp. 96-104.

34. Lertzman, R. Environmental Melancholia: Psychoanalytic Dimensions of Engagement; Routledge: London, UK; New York, NY, USA, 2015.

35. Lertzman, R. Keynote speech at Citizens' Climate Lobby. In Proceedings of the Canada's 2016 National Conference: Everything is Connected, Ottawa, QC, Canada, 26-29 November 2016; Available online: https://www.youtube.com/watch?v=VaUv9BrK32c (accessed on 4 November 2018).

36. O'brien, $\mathrm{K}$. Is the $1.5^{\circ} \mathrm{C}$ target possible? Exploring the three spheres of transformation. Curr. Opin. Environ. Sustain. 2018, 31, 153-160. [CrossRef]

37. Naess, A. Identification as a source of deep ecological attitudes. In Deep Ecology; Tobias, M., Ed.; Avant Books: San Diego, CA, USA, 1985; pp. 256-270.

38. Bragg, E.A. Towards Ecological Self: Deep Ecology Meets Constructionist Self-Theory. J. Environ. Psychol. 1996, 16, 93-108.

39. Capra, F.; Luisi, L. The Systems View of Life: A Unifying Vision; Cambridge University Press: Cambridge, UK, 2014.

40. Akama, Y. Being awake to Ma: Designing in between-ness as a way of becoming with. CoDesign 2015, 11, 262-274. [CrossRef]

41. Puig de la Bellacasa, M. Matters of Care. Speculative Ethics in More Than Human Worlds; University of Minnesota Press: Minneapolis, MN, USA, 2017.

42. Scharmer, C.O. Theory U: Leading from the Future as it Emerges, 2nd ed.; Berrett-Coehler Publishers: San Francisco, CA, USA, 2016.

43. Saarinen, E.; Lehti, T. Inducing Mindfulness Through Life-Philosophical Lecturing. In The Wiley Blackwell Handbook of Mindfulness, 1st ed.; Ie, A., Ngnoumen, C.T., Langer, E.J., Eds.; John Wiley \& Sons, Ltd.: Oxford, UK, 2014; pp. 1105-1131.

44. Takanen, T. The Power of being Present at Work: Co-creative Process Inquiry as a Developmental Approach; Aalto University: Espoo, Finland; Helsinki, Finland, 2013.

45. Ericson, T.; Kjønstad, B.G.; Barstad, A. Mindfulness and sustainability. Ecol. Econ. 2014, 104, 73-79. [CrossRef]

46. Akama, Y. A 'Way of Being' in Design: Zen and the Art of Being a Human-Centred Practitioner. Des. Philos. Pap. 2012, 1, 1-10. [CrossRef]

47. Geiger, S.M.; Grossman, P.; Schrader, U. Mindfulness and sustainability: Correlation or causation? Curr. Opin. Psychol. 2019, 28, 23-27. [CrossRef]

48. Fischer, D.; Stanszus, L.; Geiger, S.; Grossman, P.; Schrader, U. Mindfulness and sustainable consumption: A systematic literature review of research approaches and findings. J. Clean. Prod. 2017, 162, 544-558. [CrossRef]

49. Escobar-Tello, M.C. A design framework to build sustainable societies: Using happiness as leverage. Des. J. 2016, 19, 93-115. [CrossRef] 
50. Escobar-Tello, M.C.; Bhamra, T.A. Happiness and its Role in Sustainable Design. In Proceedings of the Design Connexity: 8th International Conference of the European Academy of Design, Aberdeen, UK, 31 March-3 April 2009; pp. 149-154.

51. O'Brien, C. Sustainable Happiness: How Happiness Studies Can Contribute to a More Sustainable Future. Can. Psychol./Psychol. Can. 2008, 49, 289-295.

52. Escobar-Tello, M.C.; Bhamra, T. Happiness as a harmonising path for bringing higher education towards sustainability. Environ. Dev. Sustain. 2013,15, 177-197. [CrossRef]

53. Akama, Y. Surrendering to the ocean: Practices of mindfulness and presence in designing. In The Routledge Handbook of Sustainable Design; Egenhoefer, R.B., Ed.; Routledge: London, UK; New York, NY, USA, 2018; pp. 219-230.

54. Rojas, F.; Spencer, N.; English, S. Stillness as a Competence of Design Intelligence. In Proceedings of the Design Research Society International Conference: Reforming Traditions, Reshaping Boundaries, Bangkok, Thailand, 1-5 July 2012.

55. Rojas, F.; English, S.; Young, R.; Spencer, N. Bridging Mindfulness and Design. In Proceedings of the 5th PhD in Design Research Meeting, UD16—SUR/VIVAL, Aveiro, Portugal, 1 February-18 April 2016.

56. Hyland, T. McDonaldizing Spirituality: Mindfulness, Education, and Consumerism. J. Transform. Educ. 2017, 15, 334-356. [CrossRef]

57. Kaza, S. To Save All Beings: Buddhist Environmental Activism. In This Sacred Earth: Religion, Nature, Environment, 2nd ed.; Gottlieb, R.S., Ed.; Routledge: New York, NY, USA; London, UK, 2003; pp. $296-314$.

58. Saarinen, E.; Hämäläinen, R. The Originality of Systems Intelligence. In Essays on Systems Intelligence; Hämäläinen, R., Saarinen, E., Eds.; Systems Analysis Laboratory: Espoo, Finland, 2010; pp. 9-26. Available online: http://sal.aalto.fi/publications/pdf-files/rsaa10.pdf\#view=fit (accessed on 25 February 2019).

59. Seed, J.; Macy, J.; Fleming, P.; Naess, A. Thinking Like a Mountain: Towards a Council of All Beings; New Society Publishers: Philadelphia, PA, USA, 1988.

60. Scharmer, C.O. Theory U: Leading from the Future as it Emerges, 1st ed.; SoL: Cambridge, MA, USA, 2007.

61. Kouprie, M.; Sleeswijk Visser, F. A framework for empathy in design: Stepping into and out of the user's life. J. Eng. Des. 2009, 20, 437-448. [CrossRef]

62. Mattelmäki, T.; Vaajakallio, K.; Koskinen, I. What Happened to Empathic Design? Des. Issues 2014, 30 , 67-77. [CrossRef]

63. Koskinen, I.; Zimmerman, J.; Binder, T.; Redström, J.; Wensveen, S. Design Research through Practice: From the Lab, Field, and Showroom; Morgan Kaufmann: Waltham, MA, USA, 2011.

64. Brandt, E.; Binder, T. Experimental design research: Genealogy-Intervention-argument. In Proceedings of the International Association of Societies of Design Research: Emerging Trends in Design, Hong Kong, China, 12-15 November 2007.

65. Sleeswijk Visser, F. Bringing the Everyday Life of People into Design. Ph.D. Thesis, Delft University of Technology, Delft, The Netherlands, 12 May 2009. Available online: https://repository.tudelft.nl/islandora/ object/uuid\%3A3360bfaa-dc94-496b-b6f0-6c87b333246c?collection=research (accessed on 5 September 2018).

66. Vaajakallio, K.; Mattelmäki, T. Design games in codesign: As a tool, a mindset and a structure. CoDesign 2014, 10, 63-77. [CrossRef]

67. Eriksen, M.A. Material Matters in Co-designing-Formatting \& Staging with Participating Materials in Co-design Projects, Events \& Situations. Ph.D. Thesis, Malmö University, Malmö, Sweden, 13 June 2012.

68. Miettinen, S.; Kuure, E. Designing a Multi-Channel Service Experience. Des. Manag. Rev. 2013, $24,30-37$. [CrossRef]

69. Blomkvist, J. Representing Future Situations of Service: Prototyping in Service Design; Dissertation No. 618; Linköping Studies in Arts and Science: Linköping, Sweden, 2014.

70. Boer, L.; Donovan, J. Provotypes for participatory innovation. In Proceedings of the Designing Interactive Systems Conference, Newcastle Upon Tyne, UK, 11-15 June 2012; pp. 388-397.

71. Parisi, L. Speculation. A method for the unattainable. In Inventive Methods: The Happening of the Social; Lury, C., Wakeford, N., Eds.; Routledge: New York, NY, USA, 2012; pp. 232-244.

72. Smeenk, W.; Tomico, O.; van Turnhout, K. A systematic analysis of mixed perspectives in empathic design: Not one perspective encompasses all. Int. J. Des. 2016, 10, 31-48. 
73. Xue, H.; Desmet, P. Researcher introspection for experience-driven design research. Des. Stud. 2019, 63, 37-64. [CrossRef]

74. Sustar, H.; Mattelmäki, T. Whole in One: Designing for Empathy in Complex Systems. In Proceedings of the DESIGN+POWER: No 7: Nordes 2017, Nordic Design Research Conference, Oslo, Norway, 15-17 June 2017. 